\title{
Converging flow tracer tests in fissured limestone
}

\author{
M. S. Riley ${ }^{1}$, R. S. Ward ${ }^{2}$ \& R. B. Greswell ${ }^{1}$ \\ ${ }^{1}$ School of Earth Sciences, University of Birmingham, Edgbaston, Birmingham B15 2TT, UK \\ ${ }^{2}$ The Environment Agency, National Groundwater and Contaminated Land Centre, Olton Court, \\ 10 Warwick Road, Olton, Solihull, B92 7HX, UK
}

\begin{abstract}
A Abstract tigated experimental site in a major aquifer in the UK. tests were designed specifically to produce detailed, high-resolution information about the tails of the breakthrough curves typically observed in this kind of aquifer and test. A set of mutually compatible, low detection limit tracers was identified through laboratory investigations. Two tests were carried out over distances of $20 \mathrm{~m}$ and $40 \mathrm{~m}$ along each of the two radii towards an abstraction borehole where tracer concentration was monitored. Simple dual porosity models were calibrated using the data from one test on each radius. Blind validations of these models were undertaken by attempting to predict the outcome of the second test on each radius, producing one success and one significant failure.
\end{abstract}

Keywords: diffusion, dye tracers, fractures, limestone, models

The results of tracer tests in fractured rock often deviate from those predicted by the advection-dispersion model and are characterized by tracer breakthrough curves exhibiting sharp fronts, attenuated peaks and extended tails. Dual porosity models are regularly invoked to explain this phenomenon. These models vary in their conceptualization of the physical processes involved, but all essentially assert the existence of a body of immobile or slow moving water within the rock matrix, which acts as a temporary reservoir for contaminants, in addition to the relatively fast flowing groundwater in the fissures. A mechanism governing the exchange of solute mass between the two bodies of water completes the model. Barker (1991) and Bear et al. (1993) provide detailed introductions to dual porosity models.

Zuber \& Motyka (1994) argue that at the large scale, the local geometry of the system of fractures and fissures becomes insignificant in terms of solute transport. However, as the scale of the problem decreases, geometrical considerations assume a greater importance. In continuum models the representation of fracture geometry is generally simple; often consisting of a set of parallel, similar fissures characterized by their aperture and spacing. Consequently, much research interest has focused on transport within single fissures including some recent field experiments (Novakowski \& Lapcevic 1994; Lloyd et al. 1996). Although there is evidence to suggest that the presence of irregular channels within the fissures produces non-Fickian behaviour, it is common to adopt a simple parallel plate model of each fissure in which solute transport is assumed to take place along the fissure by advection and Fickian dispersion. In a parallel plate model, the solute exchange mechanism is represented by diffusion into and out of the rock matrix at right angles to the fissure wall (e.g. Bibby 1981; Tang et al. 1981; Lever et al. 1983). Diffusion parallel to the fissure within the rock matrix is frequently ignored.

Parameter sets characterizing the parallel fissure model can often be found which produce good fits to observed tracer test breakthrough curves. However, it is well known that the diffusion coefficients required to fit this model to field data are often orders of magnitude greater than those measured using rock samples in the laboratory (Lloyd et al. 1996). Indeed, even smallscale tracer tests conducted in single fractures in the laboratory have required enhanced diffusion coefficients to model tracer behaviour (Greswell 1995). It appears that the matrix diffusion process is augmented by a number of other diffusion-like processes such as channelling within the fissure, multi-speed advective and dispersive transport induced by the presence of small fissures and cracks, and diffusion into weathered matrix and fissure fill materials. Instantaneous, non-reversible sorption of tracer onto the fissure surface is thought to contribute to the attenuation of tracer breakthrough and the subsequent reduction in tracer recovery often experienced in these tests. These extra processes are difficult to identify and their effects remain largely unquantified. Neither is it clear how these processes affect transport at increasingly larger scales in fractured media. The term 'dual porosity' suggests an underestimation of the number of attenuating processes involved. Without greater knowledge of the constituent processes and the contribution they make to large scale solute transport, the physical basis of the dual porosity model is degraded and it remains a black box model albeit a sophisticated one.

In this paper, we describe in detail a series of tracer tests designed and performed to provide high-resolution data to investigate the ability of a calibrated dual porosity model to predict solute transport at the field scale. The tests were performed at the Longwood Quarry experimental field site situated within the Lincolnshire Limestone, which forms a major aquifer 
and an important strategic national groundwater resource. The work reported here forms part of a detailed investigation into transport processes in, and properties of, dual porosity media that has involved an integrated programme of field, laboratory and computer modelling studies. The techniques applied have included core logging, geophysical logging, small scale and large scale hydraulic testing, fracture surveys and single fissure tracer tests monitored using Positron Emission Tomography (Greswell 1995; Lloyd et al. 1996).

\section{Site description}

\section{Geology}

The Longwood Quarry field site is located $12 \mathrm{~km}$ south of Lincoln between the villages of Scopwick and Blankney; grid reference [TF 062 593] (Fig. 1). The quarry is formed from excavated Lincolnshire Limestone formation of Bajocian Age. The limestone sequence dips towards the east at about $2-4^{\circ}$ and is structurally dominated by bedding (Sumbler et al. 1990). In the quarry, the bedding is gently deformed into a series of basin and dome structures with amplitude of less than $0.3 \mathrm{~m}$ and a wavelength of several metres. Lloyd et al. 1996, describe the site in some detail.

Regularly occurring at the bedding plane contacts within the sequence are solution-enlarged fissures, with observed apertures up to $30 \mathrm{~mm}$, and which are often associated with stratigraphical boundaries and the more massively bedded limestone towards the base of the sequence. Some fissures are locally infilled with loose, silty, oolitic material. Associated with the open fissures within the saturated zone are oxidized margins up to $150 \mathrm{~mm}$ wide.

Throughout the site, the most laterally extensive sub vertical fractures lie on a NNW trend forming a set that corresponds well in orientation to the principal regional faults, and which has a spacing of between $1-1.5 \mathrm{~m}$. The set contains a subset of more vertically persistent fractures having a spacing of about 15 and $20 \mathrm{~m}$. Subsidiary fracture sets can be identified in individual beds throughout the sequence, but there is no correspondence between the sets in adjacent beds and hence no obvious vertical persistence. Angled drilling indicates that the frequency of vertical fracturing decreases rapidly with depth, but that there are occasional, complex, large aperture, and heavily weathered vertical fissures.

\section{Hydrogeology}

Regional groundwater flow within the formation is down dip with an average gradient of 1:300 (Day et al. 1967). At Longwood, the saturated thickness is approximately $13 \mathrm{~m}$ although transient variations of up to $5 \mathrm{~m}$ have been measured. At the base of the limestone, the
Grantham Formation of siltstones and mudstones forms a low permeability boundary.

Within the Lincolnshire Limestone, transmissivity is variable but is typically of the order of $1000 \mathrm{~m}^{2}$ day $^{-1}$ although values as high as $10000 \mathrm{~m}^{2}$ day $^{-1}$ have been measured. Within the borehole array, values of between 130-600 $\mathrm{m}^{2}$ day $^{-1}$ have been determined using pumping tests, which also indicated enhanced transmissivity in a NW-SE direction.

Laboratory investigation of the matrix material indicated good correlation between hydraulic conductivity and porosity, but the characteristic lithological variation observed in these limestones, is reflected in the large range of values measured for these rock properties, with porosity varying between $1.6 \%$ (dense calcilutite) and $34 \%$ (highly altered oolitic grainstone), and hydraulic conductivity ranging between $10^{-11}$ and $10^{-8} \mathrm{~ms}^{-1}$. The properties within the oxidized margins adjacent to major fissures show enhanced porosity and hydraulic conductivity towards the fissure wall due to the dissolution of calcite. Porosity determinations comparing $200 \mathrm{~mm}$ lengths of rock core showed the average porosity of rock samples from the fissure faces to be $5.5 \%$ greater than of those taken from further into the rock mass, and the hydraulic conductivity three times larger. The latter determinations do however mask the variation within each sample over its length. Measurements on samples of $20 \mathrm{~mm}$ in length, which included the faces themselves, indicated that porosity reaches values of up to $34 \%$. Full details of the laboratory experiments are to be found in Greswell et al. (1998).

Detailed hydraulic testing of the experimental site has revealed that one major bedding plane fissure (at approximately $10.5 \mathrm{~m}$ below the quarry floor) is hydraulically dominant and accounts for the majority of the horizontal flow across the site (Lloyd et al. 1996).

\section{Tracer test design and operation}

\section{Borehole array}

The borehole array was designed to allow investigation of hydraulic and transport properties of the aquifer material over different scales ranging between 2 and $40 \mathrm{~m}$. To achieve this, 16 vertical boreholes were installed around a central borehole (BH1) at different distances and orientations (Fig. 1). In addition to the vertical boreholes, two angled boreholes $\left(30^{\circ}\right.$ from vertical) were installed-one orientated in a N-S direction and the other in an E-W direction. All boreholes were rotary-drilled using water flush and recovered core (93 mm diameter) was preserved for geological logging and laboratory testing. BH1 was drilled to a depth of $24.5 \mathrm{~m}$ below the floor of the quarry into the Grantham Formation. The other boreholes were terminated close 


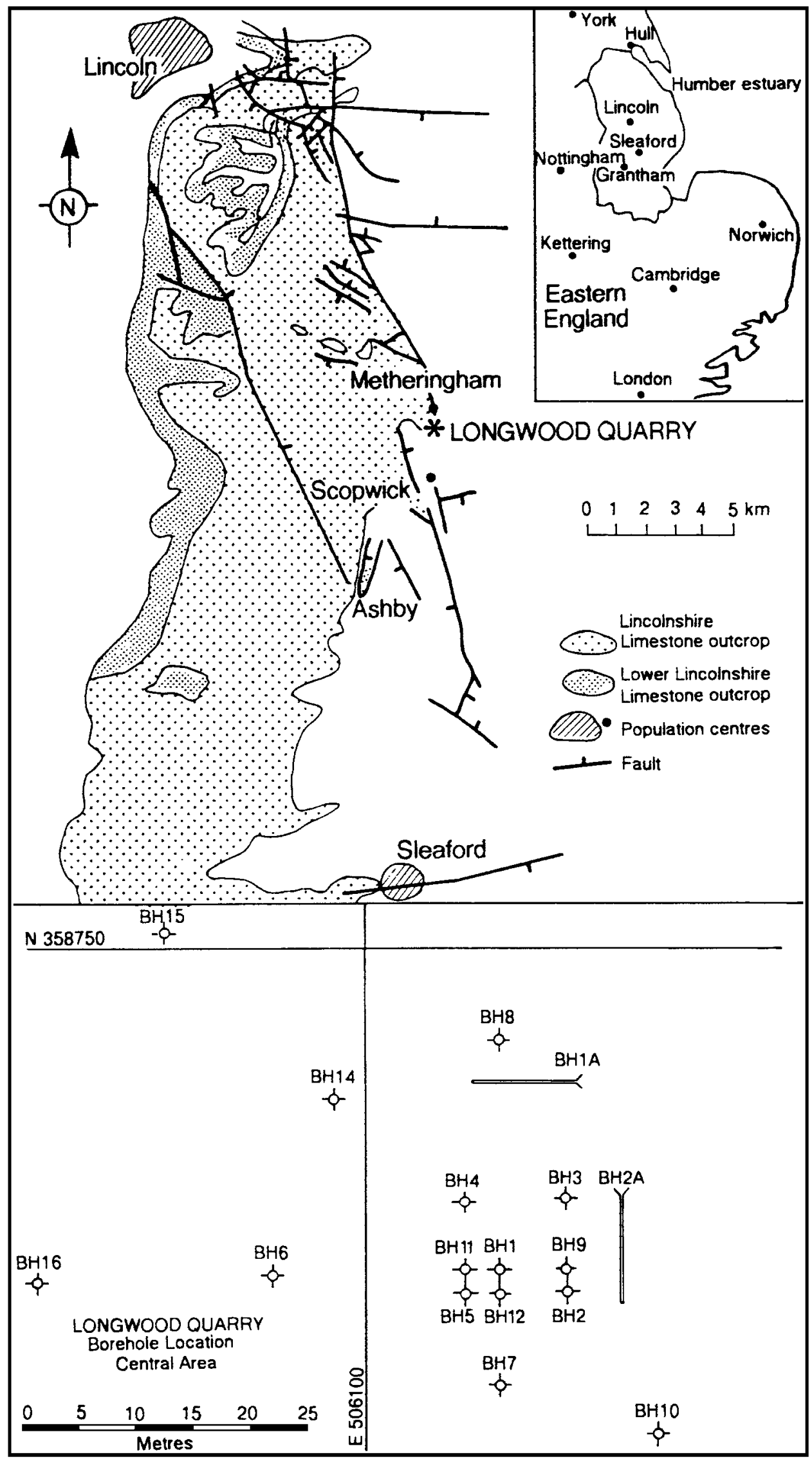

Fig. 1. Location map and borehole array, Longwood Quarry. 
Table 1. Tracer test abstraction rates and tracer data

\begin{tabular}{lcccccc}
\hline $\begin{array}{l}\text { Tracer } \\
\text { test }\end{array}$ & $\begin{array}{c}\text { Radius } \\
\text { of test } \\
(\mathrm{m})\end{array}$ & $\begin{array}{c}\text { Pumping rate } \\
\left(\mathrm{m}^{3} \mathrm{~s}^{-1}\right)\end{array}$ & $\begin{array}{c}\text { Discharge through } \\
\text { injection borehole } \\
\left(\mathrm{m}^{3} \mathrm{~s}^{-1}\right)\end{array}$ & Tracer & $\begin{array}{c}\text { Mass of } \\
\text { tracer } \\
(\mathrm{g})\end{array}$ & $\begin{array}{c}\text { Tracer } \\
\text { recovery } \\
(\%)\end{array}$ \\
\hline 1 & 20 & $5.17 \times 10^{-3}$ & $3.48 \times 10^{-5}$ & Fluoroscein & 12 & 74.4 \\
2 & 20 & $5.17 \times 10^{-3}$ & $6.85 \times 10^{-5}$ & Amino G acid & 34 & 98.6 \\
3 & 40 & $1.98 \times 10^{-3}$ & $4.08 \times 10^{-5}$ & Fluoroscein & 12 & 55.0 \\
4 & 40 & $1.98 \times 10^{-3}$ & $6.81 \times 10^{-6}$ & Amino G acid & 31 & 88.3 \\
\hline
\end{tabular}

to the bottom of the basal member of the Limestone Formation. The boreholes which have diameters of either $101 \mathrm{~mm}$ or $154 \mathrm{~mm}$ are unscreened, uncased and are open over their entire length.

\section{Tracer tests}

Four forced gradient tracer tests were performed. The tests involved the abstraction of groundwater at a constant rate from $\mathrm{BH} 1$ with tracers introduced in boreholes BH14 (Test 1) and BH6 (Test 2) at $20 \mathrm{~m}$ from BH1, and in boreholes BH15 (Test 3) and BH16 (Test 4) at a distance of $40 \mathrm{~m}$. Water levels were monitored using pressure transducers linked to a computer-controlled data logger, which allowed real-time graphical display of levels. Flow rate was monitored using an in-line flow meter connected to the discharge line with flow controlled by means of a gate valve. Once steady-state flow conditions were achieved, no adjustment in flow rate was necessary. Groundwater abstraction rates from $\mathrm{BH} 1$ and tracer data are shown in Table 1.

Tracer dilution in the injection well and tracer arrival at the abstraction well were then monitored with time. The tracer tests were run sequentially, with the $20 \mathrm{~m}$ tests performed before the $40 \mathrm{~m}$ tests. Each test was run to near completion before the start of the next test or after re-establishment of steady state flow conditions after changes in pumping rate. Monitoring of tracer breakthrough at the abstraction well was continued in each test until tracer concentrations in the groundwater had returned to pre-test background. To reduce the impact of open boreholes between the injection points and abstraction point and minimize artificially induced vertical flows, packer assemblies were installed in all intermediate boreholes (including $\mathrm{BH} 6$ and $\mathrm{BH} 14$ during the $40 \mathrm{~m}$ tests) to isolate the dominant fissure (Fig. 2).

\section{Choice of tracers}

A suite of tracers was selected satisfying the following criteria:

(1) mutual chemical and physical inertness

(2) mutual non-interference of detection
(3) low detection limits

(4) rapid, on-site analysis

(5) low or predictable sorption characteristics

(6) availability

Based upon preliminary investigation and availability of equipment, three types of tracer were evaluated in the laboratory and the field:

Single ions. Ions such as chloride, bromide and iodide have all been used as tracers in previous studies (Davis et al. 1985). Chloride is unsuitable due to its relatively high background concentration in the groundwater (often tens of $\mathrm{mg} \mathrm{1}^{-1}$; Smalley et al. 1994). Iodide was also rejected due to its tendency to sorb and undergo microbiological decay (Davis et al. 1985). Bromide (as $\mathrm{KBr}$ ) was selected for this study as it has a very low natural occurrence and is rapidly analysed using a single-ion probe. In the field, the concentration of bromide was continuously monitored using an 'Orion' single ion probe and meter attached to a flow-through cell. Using this device the concentration of bromide could be measured between $0.001 \mathrm{~g}^{-1}$ and $10 \mathrm{~g}^{-1}$.

Fluorinated organic anions. These compounds have the advantage of very low toxicity, low detection limits, conservative behaviour, and are commonly undetectable in natural waters. Laboratory evaluation of 2,6 difluorobenzoate, 2,5 difluorobenzoate, 3,4 difluorobenzoate, 3,5 difluorobenzoate and o-trifluorometylbenzoate found them to be good potential candidates for the work at Longwood. A further advantage is their compatibility with both bromide and the fluorescent dyes described below, potentially creating a large suite of tracers for simultaneous use. However, using HPLC with a UV detector, approximately 20 minutes per sample is required for analysis. In addition, early field evaluation of these tracers showed that their low solubility demanded the injection of a significant volume of tracer. Injection by pumping was avoided in this study in order to prevent disturbance of the flow field around the injection borehole, which causes enhanced dispersion in the tracer test. Time constraints precluded the development of a viable, non-disturbing continuous injection system and so these compounds were rejected. However, 


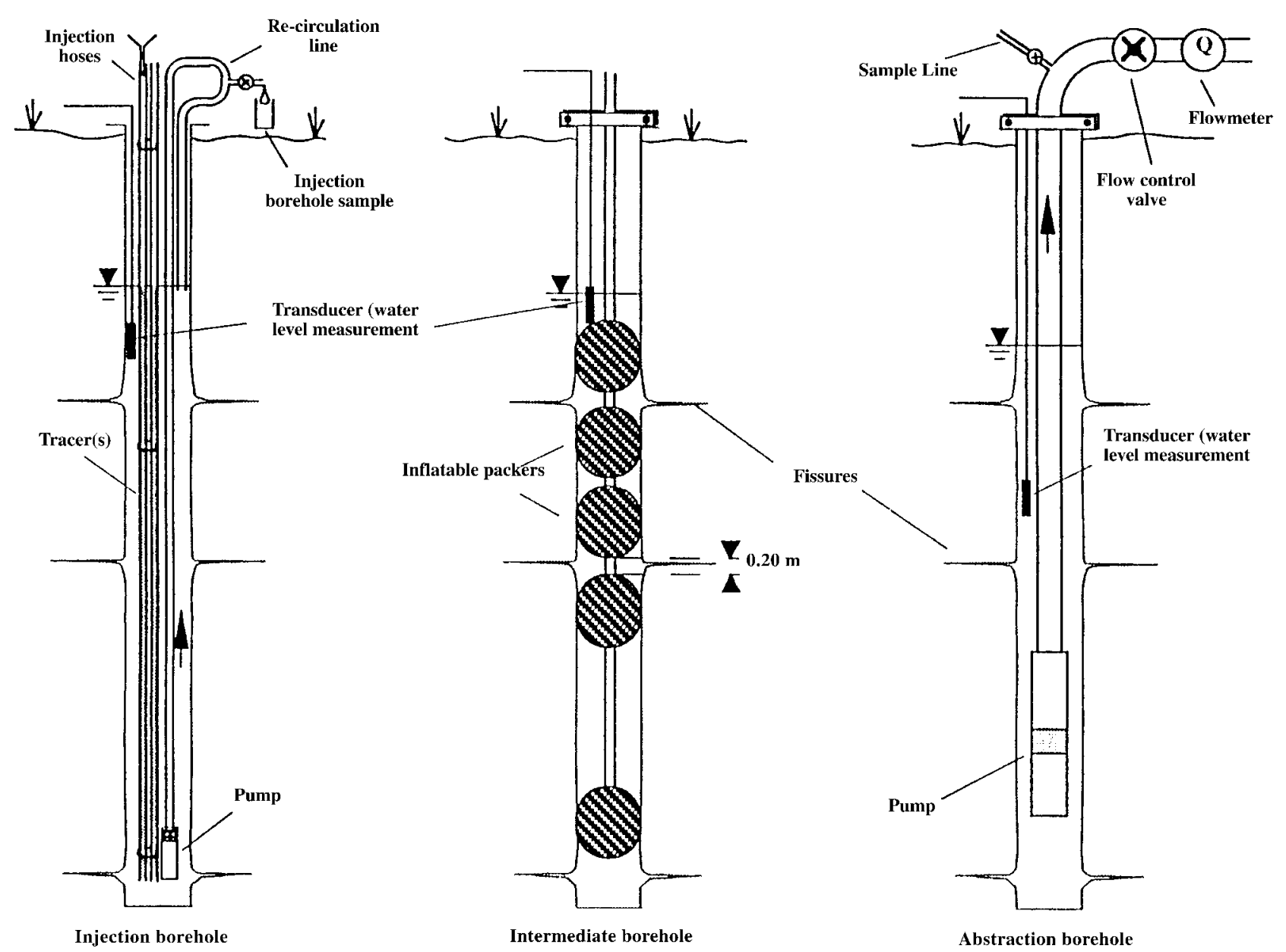

Fig. 2. Tracer test experimental layout.

with the development of a reliable injection method, they could make a valuable contribution to tracer work of this kind.

Fluorescent dyes. Fluorescent dyes were seen to have the potential to meet the requirements outlined above. They can be detected in concentrations ranging over several orders of magnitude from very low concentrations, typically $10^{-7} \mathrm{~g}^{-1}$. Each has a characteristic emission and excitation wavelength that allows them to be used simultaneously if carefully selected. Rapid analysis in the field is possible using fluorescent spectrophotometry. Whilst various dyes have been reported as useful groundwater tracers (Smart \& Laidlaw 1977; Smettem \& Trudgill 1983; Davis et al. 1985) only a limited set met the requirements for these tracer tests. Four dyes were considered: Amino G acid, fluorescein, rhodamine WT and sodium napthionate.

In the laboratory, the slight acidity of sodium napthionate and amino $\mathrm{G}$ acid, even in dilute concentrations, reduced the $\mathrm{pH}$ of a dye mixture to 6.5 or below, a critical level at which fluorescein undergoes a structural change to a colourless form. Above this $\mathrm{pH}$ the fluorescent form is stable (Smart \& Laidlaw 1977). However, it was found that the buffering effect of the groundwater from Longwood was sufficient to maintain the $\mathrm{pH}$ at around 7.0 even at concentrations of $1.0 \mathrm{~g}^{-1}$ of the acidic dyes.

Using groundwater as a solute and zero reference, the lower and upper limits of concentration measurement, relative fluorescent intensity and peak spectral responses were ascertained using a Hitachi F2000 fluorescence spectrophotometer (Table 2). When used in a mixture, the dyes must have sufficiently separate spectral responses to avoid interference. Compatibility was tested by examining the level of emission from a $1.0 \times 10^{-3} \mathrm{~g}$ $1^{-1}$ solution of each dye at each of the other dyes' characteristic wavelengths using distilled water as the zero reference. The results shown in Table 3 indicate that sodium napthionate and amino $G$ acid are incompatible due to relative emissions significantly above natural groundwater levels. Due to supply problems, sodium napthionate was not considered further.

The fluorescence of the dyes tested is known to vary inversely with temperature (Smart \& Laidlaw 1977). In the field, the spectrophotometer was calibrated with standards maintained at the ambient groundwater temperature avoiding the need to apply a correction factor. 
Table 2. Lower and upper limits of concentration measurement, relative fluorescein intensity and peak spectral responses for fluorescent dyes

\begin{tabular}{llcccccc}
\hline Dye & \multicolumn{1}{c}{$\begin{array}{c}\text { Chemical } \\
\text { formula }\end{array}$} & $\begin{array}{c}\text { Peak } \\
\text { excitation } \\
\text { wavelength } \\
(\mathrm{nm})\end{array}$ & $\begin{array}{c}\text { Peak } \\
\text { emission } \\
\text { wavelength } \\
(\mathrm{nm})\end{array}$ & $\begin{array}{c}\text { Emission } \\
\text { colour }\end{array}$ & $\begin{array}{c}\text { Emission } \\
\text { intensity } \\
\text { (relative to } \\
\text { fluorescein) }\end{array}$ & $\begin{array}{c}\text { Approximate } \\
\text { upper working } \\
\text { concentration } \\
\left(\mathrm{g} \mathrm{1^{-1 }}\right)\end{array}$ & $\begin{array}{c}\text { Approximate } \\
\text { detection } \\
\text { limit } \\
\left(\mathrm{g} \mathrm{1^{-1 }}\right)\end{array}$ \\
\hline Rhodamine WT & $\mathrm{C}_{29} \mathrm{H}_{30} \mathrm{O}_{5} \mathrm{~N}_{2} \mathrm{Na}$ & 554 & 578 & Red & 0.25 & $2 \times 10^{-2}$ & $2 \times 10^{-8}$ \\
Fluorescein & $\mathrm{C}_{20} \mathrm{H}_{10} \mathrm{O}_{5} \mathrm{Na}_{2}$ & 488 & 512 & Green & 1.0 & $1 \times 10^{-3}$ & $2 \times 10^{-7}$ \\
Amino G acid & $\mathrm{C}_{10} \mathrm{H}_{9} \mathrm{NO}_{6} \mathrm{~S}_{2}$ & 353 & 447 & Blue & 0.12 & $2 \times 10^{-2}$ & $2 \times 10^{-6}$ \\
Sodium napthionate & $\mathrm{C}_{10} \mathrm{H}_{8} \mathrm{O}_{3} \mathrm{~N} \mathrm{~S} \mathrm{Na}^{-2}$ & 324 & 418 & Violet & 0.16 & $2 \times 10^{-2}$ & $2 \times 10^{-6}$ \\
\hline
\end{tabular}

Obtained using Hitachi F2000 fluorescence spectrophotometer.

Table 3. Compatibility of fluorescent dyes

\begin{tabular}{lcccc}
\hline Substance under test & \multicolumn{3}{c}{ Relative emission at the characteristic wavelengths of } \\
\cline { 2 - 5 } & Amino G acid & Sodium napthionate & Rhodamine WT & Fluorescein \\
\hline Amino G acid & 1.0 & 0.22 & 0.0008 & 0.001 \\
Sodium napthionate & 0.18 & 1.0 & 0.0007 & 0.0009 \\
Rhodamine WT & 0.0015 & 0.002 & 1.0 & 0.002 \\
Fluorescein & 0.0012 & 0.015 & 0.0025 & 1.0 \\
Longwood groundwater & 0.002 & 0.002 & 0.0005 & 0.001 \\
\hline
\end{tabular}

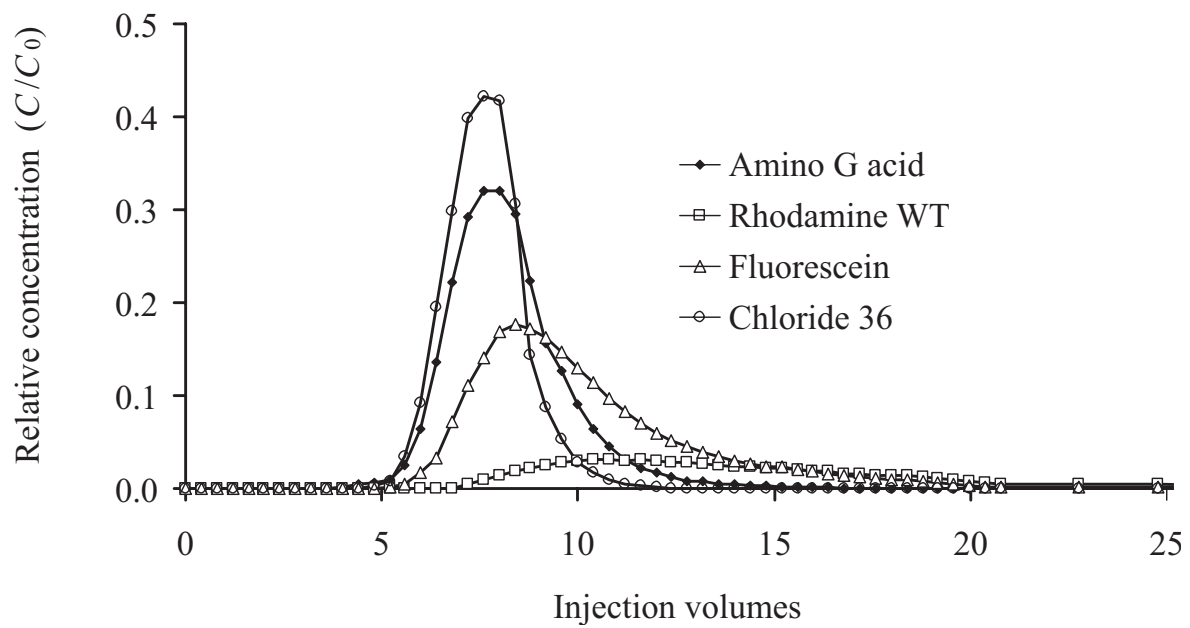

Fig. 3. Fluorescent dye breakthrough curves from column experiments with altered limestone.

Dye adsorption was quantified in column experiments using ground aquifer material, with particle size in excess of $1.0 \mathrm{~mm}$, consisting of unaltered limestone; altered (buff) limestone; and fill material packed as a 1:1 mixture with altered limestone. Following a 5-hour period of stabilization during which groundwater was passed through the column, $1.0 \times 10^{-3} \mathrm{~g}^{-1}$ solutions of the dyes amino $\mathrm{G}$ acid, rhodamine WT and fluorescein were introduced as a pulse together with a conservative tracer, ${ }^{36} \mathrm{Cl}$. Groundwater was then re-introduced during the elution phase. A separate experiment determined that there was no interference from the dyes during the scintillation analysis of ${ }^{36} \mathrm{Cl}$. Elution continued for around 18 hours (representing approximately 14 pore volumes) with dye concentration analysed by spectrophotometry.

Figure 3 shows the breakthrough curves from the column experiment containing altered limestone. It is interesting to note that the simple model of advection, dispersion and linear equilibrium sorption does not adequately describe the observed behaviour in these experiments. To obtain good fits to the data, the simple model demands the dispersion parameter to be enhanced with increased retardation. The observations that dye 
Table 4. Results of column experiments with fluorescent dyes

\begin{tabular}{lccc}
\hline Dye & \multicolumn{3}{c}{ Contents of column } \\
\cline { 2 - 4 } & $\begin{array}{c}\text { Unaltered } \\
\text { limestone }\end{array}$ & $\begin{array}{c}\text { Altered } \\
\text { limestone }\end{array}$ & $\begin{array}{c}1: 1 \text { mix altered } \\
\text { limestone and } \\
\text { fracture fill material }\end{array}$ \\
& & & \\
\hline $\begin{array}{c}\text { Fluorescein } \\
\text { \% Recovery }\end{array}$ & 82.6 & 90.8 & 75.0 \\
$T_{R}$ & 1.30 & 1.11 & 1.56 \\
$\begin{array}{c}\text { Amino G acid } \\
\% \text { Recovery }\end{array}$ & 100.2 & 100.9 & 108.6 \\
$T_{R}$. & 1.04 & 1.03 & 1.00 \\
Rhodamine WT & & & \\
$\%$ Recovery & 14.6 & 41.8 & 23.1 \\
$T_{R}$ & 3.91 & 1.47 & 5.25 \\
\hline
\end{tabular}

recovery is as low as $14 \%$ and that retardation and recovery appear to be negatively correlated indicate clearly that more complex processes are involved. The explanation of this behaviour is not pursued further here. Instead, an indication of the relative retardation behaviour of the dyes is provided by $T_{R}$, the time to peak breakthrough relative to that of chloride. Table 4 summarized the results of the adsorption experiments. The column experiments indicate that amino $G$ acid behaves conservatively with all the aquifer material tested. Fluorescein showed some tendency to sorb, with rhodamine WT having marked sorption. The most active sites for sorption are associated with the grey fracture fill material and the unaltered limestone. Rhodamine WT was not used in the field tracer tests described in this paper due to concerns of nonconservative behaviour and minor interference with fluorescein, but had previously been used at Longwood (Lloyd et al. 1996) where direct comparison with bromide indicated no apparent retardation. Similarly, direct comparisons between bromide and fluorescein showed that under field conditions fluorescein behaved conservatively.

\section{Tracer injection}

Injecting a tracer by pumping, raises the head near the injection borehole creating radial flow components that produce an enhanced dispersion in the test system. Instead, tracer was introduced into the injection borehole using two hoses, which extended from the ground surface to the bottom of the borehole. The hoses were filled with tracer solution and then withdrawn leaving a standing column of tracer in the borehole. The tracer within the borehole was continuously mixed using a pre-installed recirculation system in which water was pumped from the bottom of the borehole to the ground surface and back to just below the water surface in the borehole. The tracer solution in the injection borehole was sampled at the surface by tapping the recirculation line (Fig. 2).

In each of the first two tracer tests, which were conducted at $20 \mathrm{~m}$, a fluorescent dye and bromide were injected simultaneously. During these tests, the two tracers behaved identically. However, the quality of the fluorescent dye data was superior due to the lower detection limit. Subsequently, Bromide was used in preliminary tracer tests at $40 \mathrm{~m}$ to allow first arrival time and the time to peak concentration to be estimated prior to the full tracer test and enabling the sampling frequency to be optimized. Injection of fluorescent tracers took place shortly after peak arrival of the bromide. This method worked well and removed considerable uncertainty, especially since in one test tracer breakthrough occurred sooner than expected.

\section{Abstraction well sampling}

The discharge pipe from the abstraction borehole was tapped immediately above the ground surface by a narrow diameter $(4 \mathrm{~mm})$ sample line. The sample line was extended to the mobile laboratory positioned $2.5 \mathrm{~m}$ from the abstraction well (Fig. 2). Tubing lengths were minimized to reduce dead volumes and errors in the concentration data. Since amino G acid is especially susceptible to rapid photo-decay under field conditions, the sampling tube on the well discharge pipe was shielded from sunlight. During the tracer test, a continuous flow through the sample line of $200 \mathrm{ml} \mathrm{min}^{-1}$ was maintained. The sample line was split two ways with one line going to the flow-through cell of a fluorescence spectrophotometer and the other to a flow-through cell of a bromide ion specific electrode. This allowed immediate sample analysis and, with a closed system, reduced the likelihood of cross-contamination.

Immediate data transfer to a PC provided real-time graphical display of tracer breakthrough and digital data storage. This enabled the performance of the tracer test to be monitored continuously, allowing modifications to be made to sampling frequencies and other experimental conditions as appropriate.

\section{Tracer Test analysis}

The tests produced a set of detailed tracer breakthrough curves, which are shown in Figures 4, 7, 9 and 10. The presence of one dominant bedding plane fissure across the experimental site within which the majority of flow takes place suggests an initial, simple conceptual model of the system as a single horizontal fissure. Evidence supporting this model was provided by water samples taken during the tests from above the packers in the intermediate boreholes (BH11 and $\mathrm{BH} 4)$, which revealed 


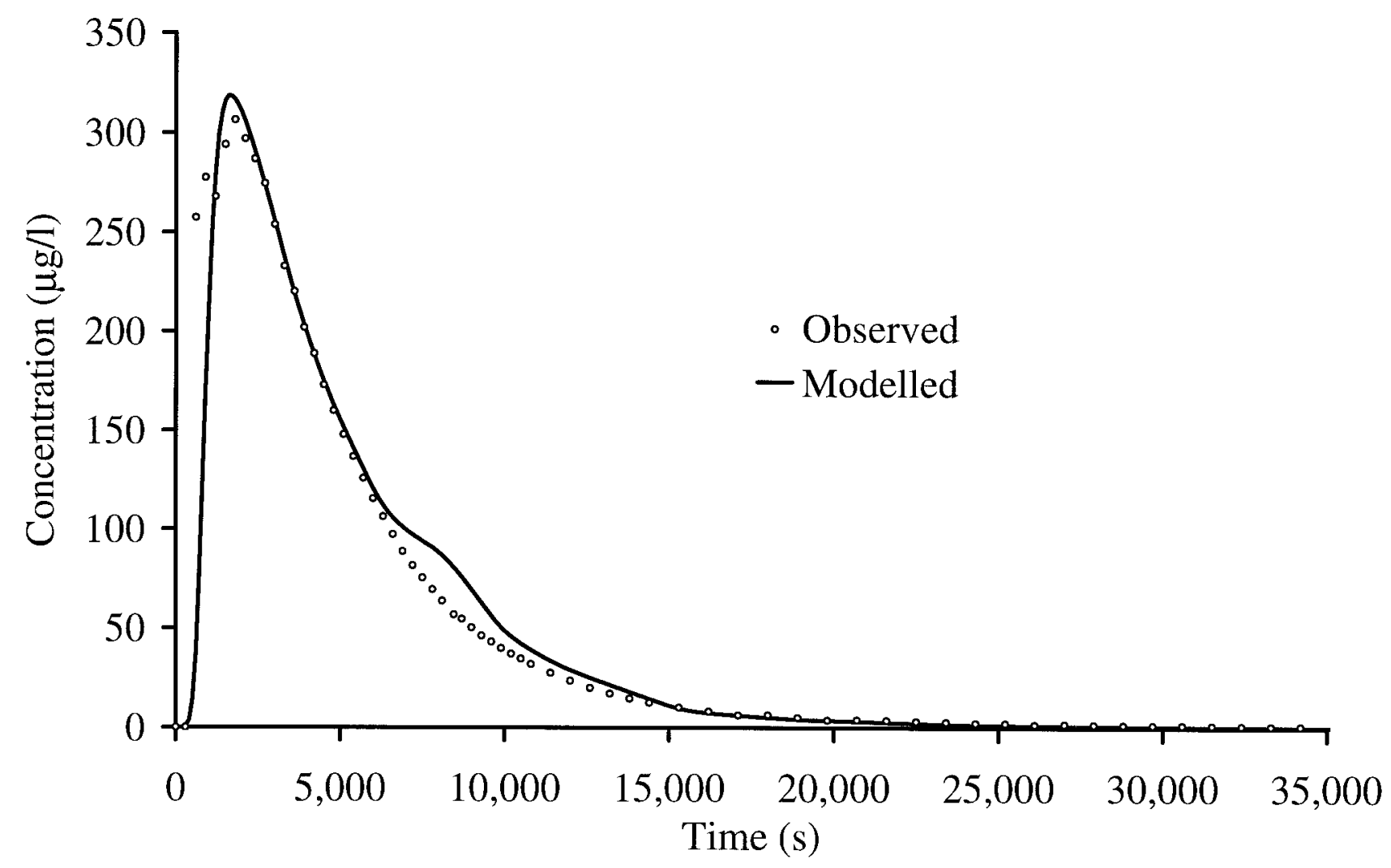

Fig. 4. Observed and modelled tracer breakthrough curves for Test 1.

no tracer. Flow through the bedding plane fissures at greater depth does occur, but slug test results indicate that it is small compared with that in the dominant fissure (Lloyd et al. 1996).

Numerous authors have given the mathematical formulation of transport in a single fissure. The following formulation for non-sorbing, conservative tracer transport has been adapted from the more comprehensive equations given by Tang et al. (1981).

The mass balance equation in the fissure is

$$
\frac{\partial c}{\partial t}+u \frac{\partial c}{\partial x}-D \frac{\partial^{2} c}{\partial x^{2}}-\left.\frac{\theta D_{d}}{b} \frac{\partial c^{\prime}}{\partial z}\right|_{z=b}=0
$$

where $c$ is the contaminant concentration in the fissure

$c^{\prime}$ is the contaminant concentration in the matrix

$\left[\mathrm{ML}^{-3}\right]$

$c^{\prime}$ is the contaminant concentration in the mat

$x$ is the distance along the fissure

$z$ is the distance into the matrix perpendicular to the fissure

$u$ is the advective velocity of the water in the fissure

$\left[\mathrm{LT}^{-1}\right]$

$D$ is the hydrodynamic dispersion coefficient given here as the product of the dispersivity and the advective velocity

$\left[\mathrm{L}^{2} \mathrm{~T}^{-1}\right]$

$D_{d}$ is the apparent matrix diffusion coefficient given by the product of the free water diffusion coefficient and a tortuosity factor

$\left[\mathrm{L}^{2} \mathrm{~T}^{-1}\right]$ $\theta$ is the bulk porosity of the matrix

The mass balance equation in the matrix is

$$
\frac{\partial c^{\prime}}{\partial t}-D_{d} \frac{\partial^{2} c^{\prime}}{\partial z^{2}}=0
$$

Simulation of the tracer tests was conducted using a finite element computer code based upon Equations 1 and 2. Dispersion within the injection borehole was accounted for explicitly by using the time series of measured concentrations in the injection borehole as the input to the model. This time series was also used to calculate the discharge, $Q_{i n j}$, through the injection borehole, assuming complete mixing within the borehole, by

$$
Q_{i n j}=\frac{M}{\int_{0}^{\infty} c(0, t)-c_{0} \mathrm{~d} t}
$$

where $M$ is the total mass of tracer injected

$c(0, t)$ is the tracer concentration in the injection borehole at time $t$, and

$\left[\mathrm{ML}^{-3}\right]$

$c_{0}$ is the background concentration of tracer (assumed to be zero)

$\left[\mathrm{ML}^{-3}\right]$

Analysis of the dilution of the tracer in each of the injection boreholes indicated flow to the central well to be highly non-radial, and consequently each test was modelled as a single stream tube from the injection to the 
Table 5. Calibrated model parameters

\begin{tabular}{lcccc}
\hline $\begin{array}{l}\text { Tracer } \\
\text { test }\end{array}$ & $\begin{array}{c}\text { Radius } \\
\text { of test } \\
(\mathrm{m})\end{array}$ & $\begin{array}{c}\text { Dispersivity } \\
(\mathrm{m})\end{array}$ & $\begin{array}{c}\text { Matrix } \\
\text { diffusion } \\
\text { coefficient } \\
\left(\mathrm{m}^{2} \mathrm{~s}^{-1}\right)\end{array}$ & $\begin{array}{c}\text { Fracture } \\
\text { aperture } \\
(\mathrm{m})\end{array}$ \\
\hline 1 & 20 & 2.0 & $5.5 \times 10^{-9}$ & 0.018 \\
2 & 20 & - & - & - \\
3 & 40 & 2.0 & $7.2 \times 10^{-7}$ & 0.030 \\
4 & 40 & 2.0 & $5.5 \times 10^{-9}$ & 0.034 \\
\hline
\end{tabular}

abstraction borehole. Distortion of the flow field in the vicinity of the injection borehole caused by the presence of the borehole itself (e.g. Drost et al. 1968) affects breakthrough at the abstraction borehole (Zlotnik \& Logan 1996). The associated advective spreading of tracer near the injection hole can be characterized by a factor, $\alpha$, the ratio of the maximum width of the advective plume to the diameter of the borehole. Alternatively, $\alpha$ can be considered to be the ratio of the discharge through the borehole to the discharge through a circular area of rock with the same radius. Theoretically, if the borehole is located in an otherwise uniform or radial flow field in a homogeneous porous medium, a is equal to 2 . This value of a has been used in the modelling.

The modelled breakthrough curves were scaled by a factor representing the dilution in the abstraction borehole and the loss of tracer mass during the test. Calibration was then carried out using three effective parameters: dispersivity, fracture aperture and matrix diffusion coefficient. A summary of the results of the calibration exercise is shown in Table 5.

In order to test the predictive capability of this simple transport model, a blind validation exercise was envisaged for each pair of tests on the same radial arm from the abstraction borehole in which calibration was to be conducted on the $20 \mathrm{~m}$ test followed by prediction of the $40 \mathrm{~m}$ test results.

\section{Tests 1 and 3}

The observed breakthrough curve for Test 1 , conducted over a distance of $20 \mathrm{~m}$, is shown in Figure 4. Figure 4 also shows the modelled breakthrough curve produced by calibration. The parameters determined from this calibration were then used in conjunction with the injection data from Test 3 in a blind test to predict Test 3 breakthrough. In predicting the concentrations for Test 3, the percentage of tracer recovered during Test 1 was assumed to apply to the predicted results. Test 3 was carried out in the same orientation as Test 1 but over a distance of $40 \mathrm{~m}$. Although the calibrated fit to the Test 1 data is quite good (Fig. 4), the consequent prediction, shown in Figure 5, is poor.
The field team noted a similar mismatch between a simple advective model prediction and the data. The pumping rate in the $20 \mathrm{~m}$ test was $3101 \mathrm{~min}^{-1}$ whereas in the $40 \mathrm{~m}$ test the pumping rate was reduced to 1191 $\min ^{-1}$. Thus, assuming radial flow and advective transport, the transit time of the tracer in the $40 \mathrm{~m}$ test should have been around 10 times that in the $20 \mathrm{~m}$ test. In reality, initial breakthrough in the $40 \mathrm{~m}$ test took only about 5 times longer than that observed in the $20 \mathrm{~m}$ test. The time to peak concentration in the larger scale test was just 3 times greater than that in the $20 \mathrm{~m}$ test.

Figure 6 shows the decay of tracer in the injection boreholes for the two tests and illustrates that tracer concentration in the outer borehole decayed faster than that in the inner hole indicating a higher discharge through the $40 \mathrm{~m}$ borehole in spite of the greater distance and reduced pumping rate. Since the same tracer injection procedure was carried out for both tests, and there were no substantial changes in ambient conditions during the test period, it is assumed that this strongly non-radial behaviour is a function of the spatial variability of the hydraulic properties of the test site.

Following the blind validation test, a model was fitted to the data from Test 3 by calibration. Figure 7 shows the results of the calibration. The fit is excellent, highlighting both the flexibility of the simple three-parameter model and the concomitant danger of accepting good calibration statistics alone as convincing evidence of an adequate model.

\section{Tests 2 and 4}

The injection data for amino $\mathrm{G}$ acid from Test 2 are shown in Figure 8. The reason for the sharp drop in tracer concentration in the injection borehole is unclear. Since an identical step was observed in the bromide data, it appears not to be due to a simple error in the tracer analysis. Furthermore, since care was taken to ensure continuous recirculation within the borehole, and the experiment had been running for a considerable time, a sampling error related to inadequate mixing is also unlikely. Whatever the cause, the effect on model calibration is significant. The observed breakthrough curve is very smooth, but all models of the test reproduced an attenuated form of the step seen in the injection data at the abstraction borehole giving a lowered tail to the breakthrough curve. Since the shape of the tail is significant in the calibration process, in particular in the determination of the diffusion coefficient, satisfactory calibration using the dual porosity model was not possible in this test. However, dual porosity calibration could be achieved from the results of Test 4 (Fig. 9), and the parameters so determined, and the percentage tracer recovery from Test 4 , were used to predict the outcome of Test 2 . The prediction, which is 


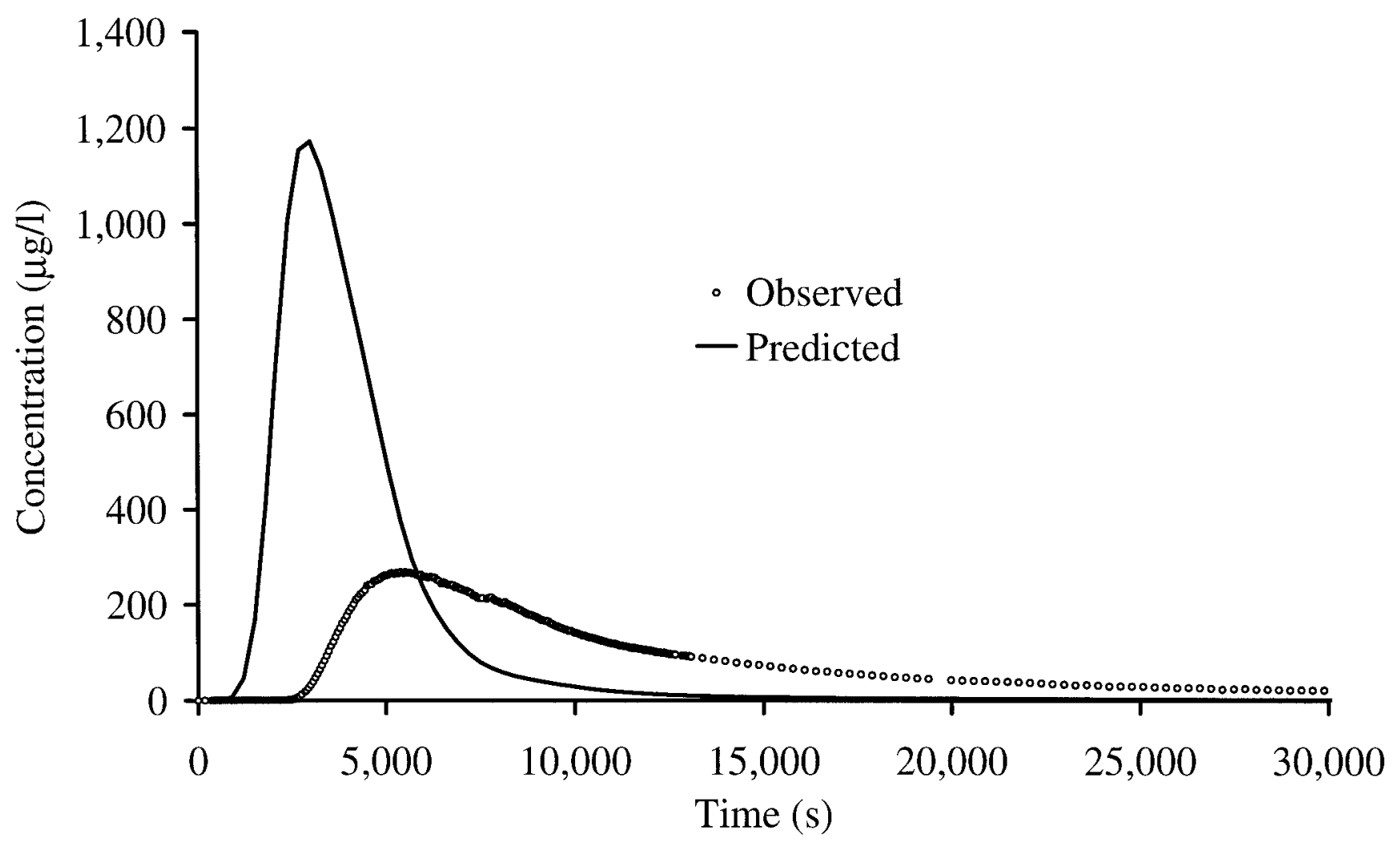

Fig. 5. Observed tracer breakthrough curve from Test 3 and predicted breakthrough curve using calibration parameters from Test 1.

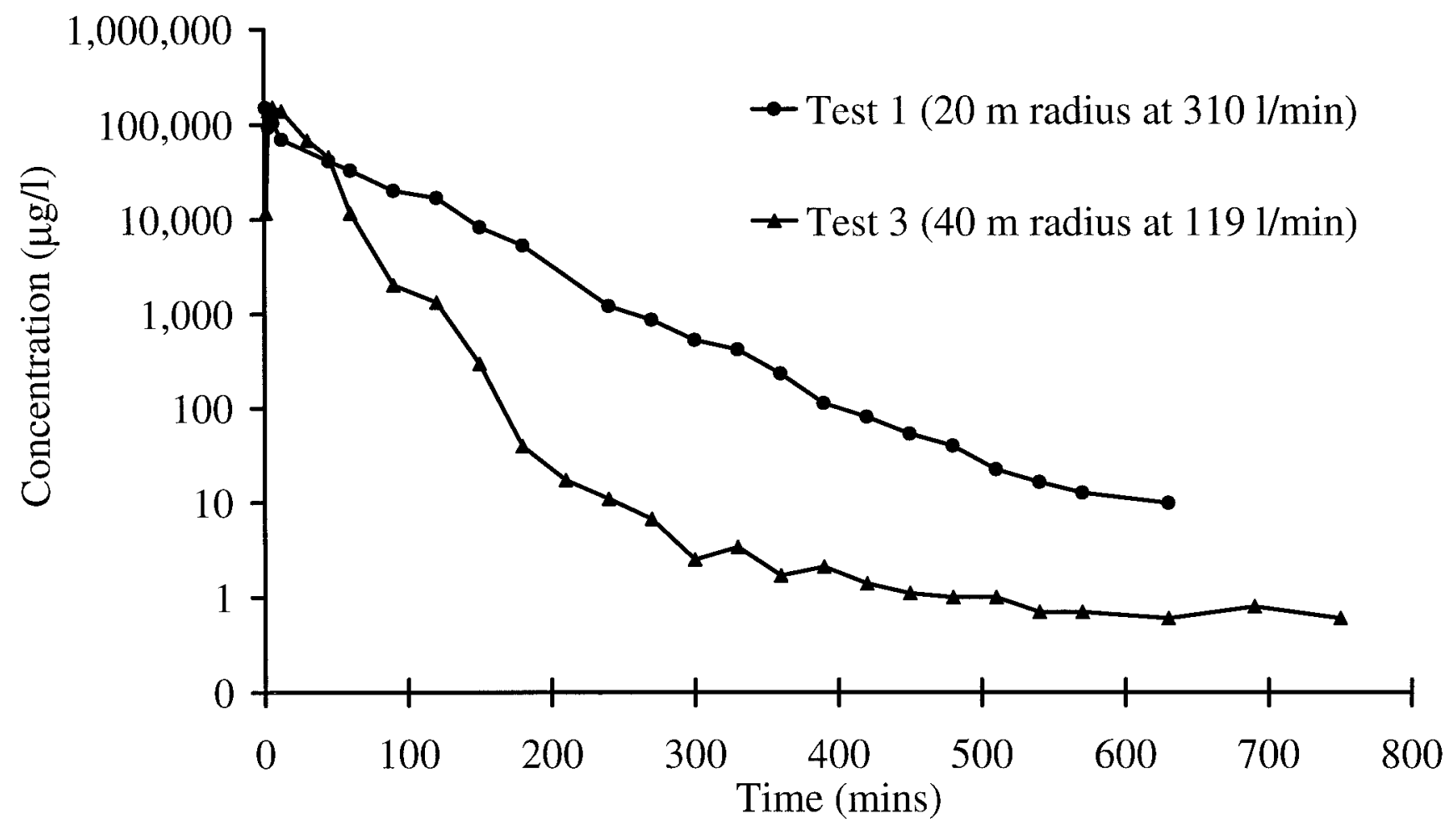

Fig. 6. Fluorescein concentrations in $\mathrm{BH} 4$ and $\mathrm{BH} 14$ during Tests 1 and 3. 


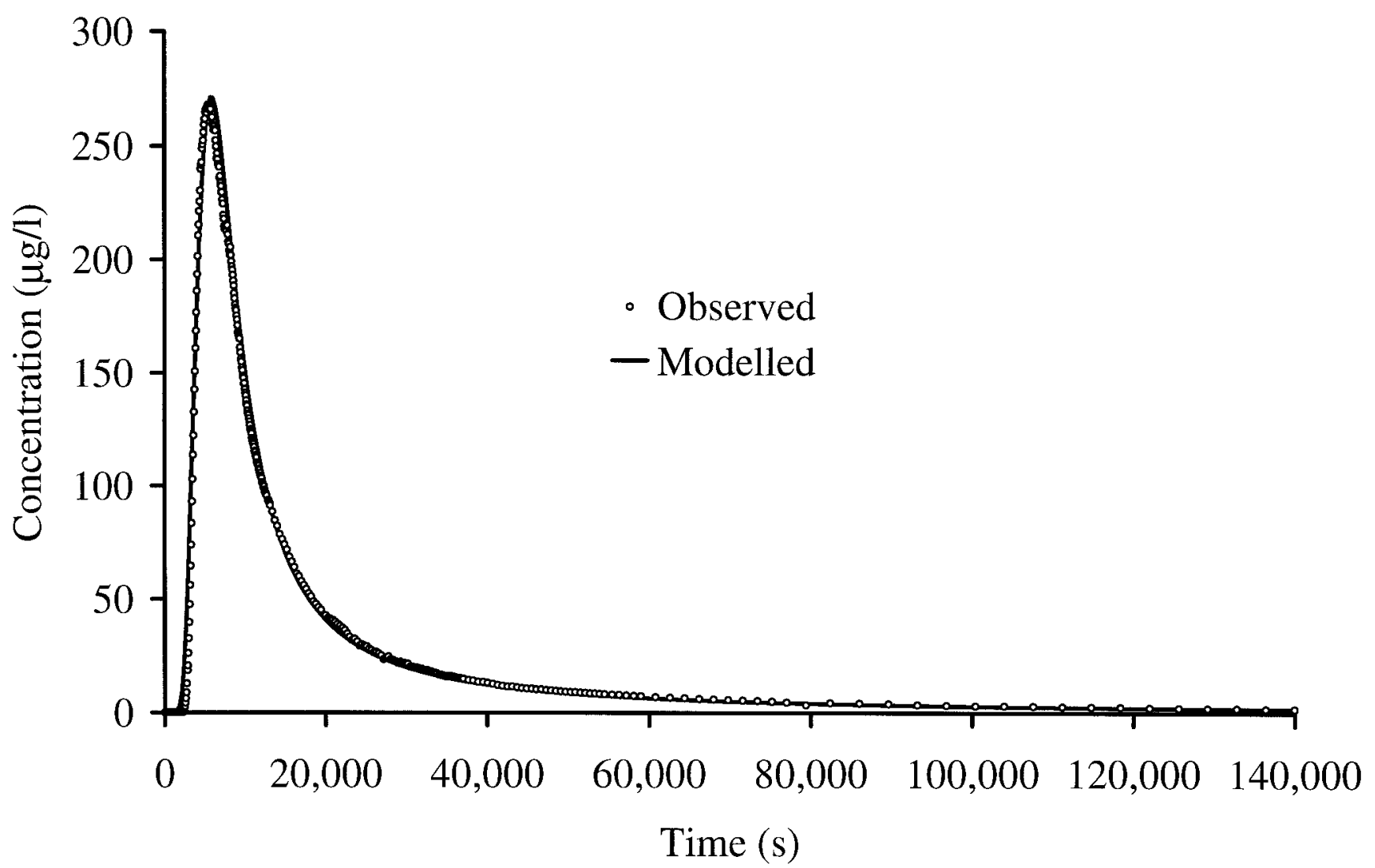

Fig. 7. Observed and modelled tracer breakthrough curves for Test 3.

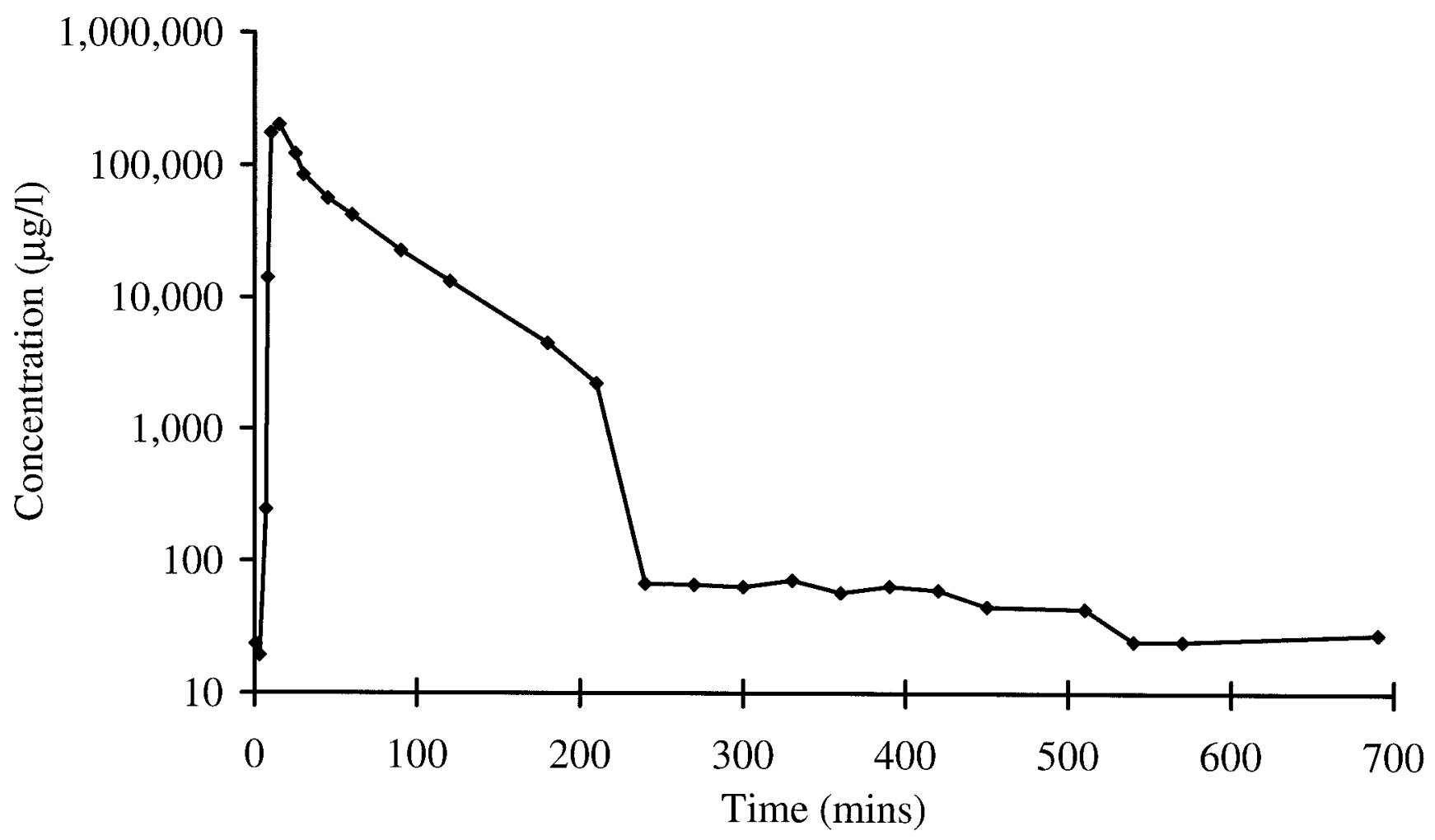

Fig. 8. Amino $\mathrm{G}$ acid concentration in BH6 during Test 2. 


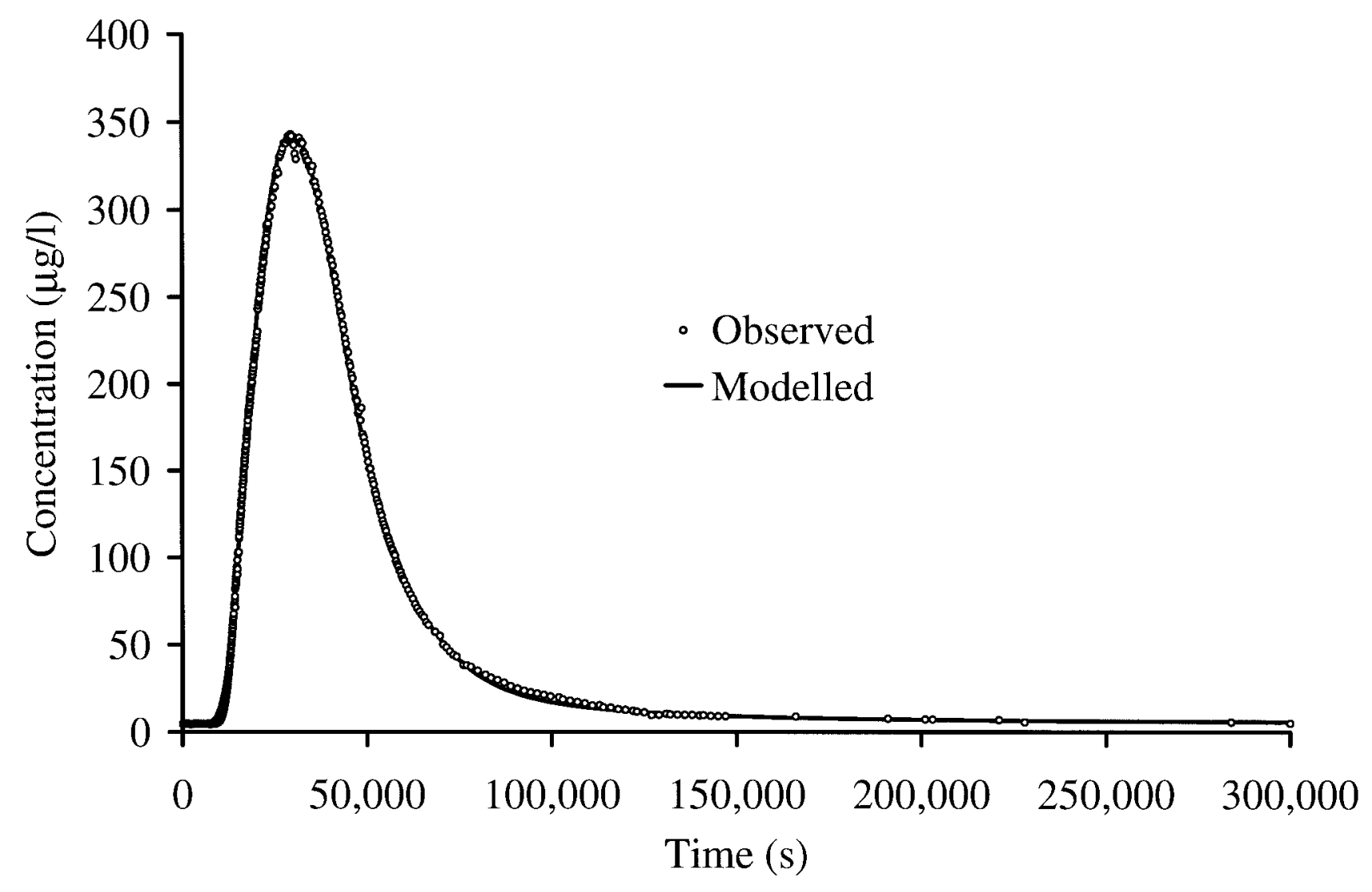

Fig. 9. Observed and modelled tracer breakthrough curves for Test 4.

shown against the observed breakthrough in Fig. 10, is reasonable overall, exhibiting an excellent match to initial breakthrough.

\section{Discussion}

This study raises a number of issues relating to conceptual models of solute transport in fissured aquifers. Numerical modelling confirms that an advectiondispersion model is inadequate to describe the observed breakthrough curves, and in addition, demonstrates that a simple dual porosity model can produce excellent fits to breakthrough data.

The flow regime created by pumping was found to be highly non-radial. Point dilution analysis of the injection borehole data indicated discharges ranging between 3.5 and 21.5 times those to be expected in a radial flow model with $\alpha=2$. The highest of these discharge values (by a factor of 3 ) is from borehole 15 , which lies to the NW of the abstraction well, i.e. along a radius corresponding well in orientation to the dominant fracture set seen in the quarry walls and to the principal regional faults, and in the direction of the highest transmissivity determined from full depth pumping tests. The indication is that the anisotropy is likely to be a function of the vertical fissures in the NW direction. Observation suggests that the scale of these features may exceed that of the tests. Thus, on the scale of the experimental array, it is unlikely that the anisotropy can be described adequately by a transmissivity tensor. We therefore adopted a stream tube model.

An immediate consequence of the stream tube approach is that transverse dispersion is neglected. In a radial, single porosity model of the system this would be inconsequential, but in a dual porosity aquifer, transverse dispersion increases the contact area between tracer and rock, enhancing breakthrough tailing. We would expect, therefore, the model matrix diffusion parameter to have to be increased in order to compensate. Fissure surfaces at the site show evidence of the presence of channelling of flow, and simulations of advective transport under converging flow using a channel network model indicate that solutes may indeed spread quite extensively laterally, albeit at very low concentrations. The effect of transverse mixing in the non-radial flow conditions observed in the tests is equivocal, and depends upon the relative magnitude of the groundwater velocity in the adjacent stream tubes.

Breakthrough curves produced by the stream tube model are sensitive to fluctuations in tracer concentration in the injection borehole. For example, the small hump in the modelled breakthrough curve for Test 1, shown in Figure 4, is produced by the elevated concentration value at 120 minutes shown in Figure 6. It is not 


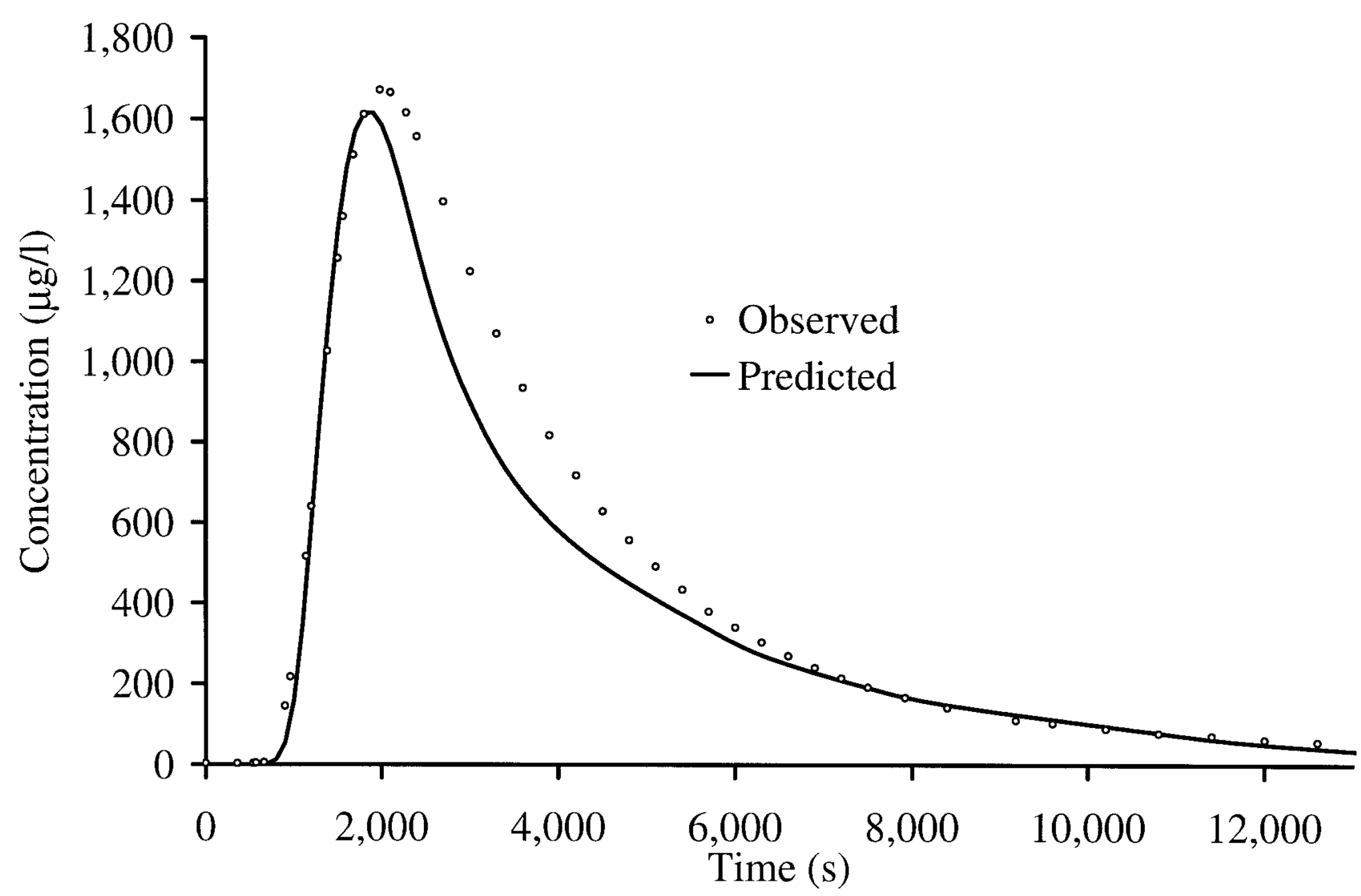

Fig. 10. Observed tracer breakthrough curve from Test 2 and predicted breakthrough curve using calibration parameters from Test 4.

clear whether the model fails to capture the smoothing behaviour of the natural system, or whether there is a disparity between the tracer concentration measured above ground at the injection borehole and the concentration of tracer in the groundwater flowing into the rock.

The longitudinal dispersion coefficient is taken to be the product of a constant dispersivity and velocity. The validity of this assumption is open to question in the vicinity of the abstraction well, where the Peclet number is very high, and turbulent and inertial effects may become significant, and indeed there is evidence to suggest that flow close to the well could be non-Darcian (Lloyd et al. 1996). However, the effect of a changing flow regime has not been considered further in this work.

Greswell et al. (1998) calculate the free water diffusion coefficient for $\mathrm{KBr}$ to be $1.7 \times 10^{-9} \mathrm{~m}^{2} \mathrm{~s}^{-1}$. The equivalent coefficients for fluorescein and amino $\mathrm{G}$ acid are smaller due to their larger molecular diameter. However, the values of the apparent matrix diffusion coefficient, $D_{d}$, required to calibrate the model are approximately $5 \times 10^{-9} \mathrm{~m}^{2} \mathrm{~s}^{-1}$ in three tests and two orders of magnitude larger in the fourth. Estimated tortuosity for the oxidized zones (Greswell et al. 1998) is on average about 0.1 implying that, in the most favourable tests, the matrix diffusion parameter in the model is about 30 times larger than the equivalent coefficient measured in the laboratory. The potential causes of the discrepancy are numerous and have been rehearsed by many. We have already noted the effects of channelling and transverse dispersion. Other candidates include alternative transport pathways through the system at the scale of the test, and within the main fissure, the existence of complex surface geometries (observed during the drilling of angled boreholes), micro-scale surface properties, and particularly the presence of highly porous fill material.

In spite of the limited physical basis of the mathematical model and its unsophisticated nature compared with the complexity of the aquifer, the dispersivity and matrix diffusion parameters obtained from Tests 1 and 4 are identical, and the quality of the prediction of Test 2 from Test 4 is good.

However, it is perhaps salutary to note that, even with detailed and extensive field and laboratory investigations, including controlled and well-monitored tracer tests, our attempts to predict solute transport may fail at the simplest and most fundamental level. The disparity between Test 3 and the other tests highlights that, although on some occasions we can get it right, in general we are unable to predict with confidence even 
the average advective behaviour of a solute. Certainly no model based upon assumptions of aquifer homogeneity could have successfully predicted the outcome of Test 3 from that of any other. The nature of the additional investigations that would have to have been undertaken in order to allow good prediction is unclear. It is perhaps worth reiterating the call for further research into the development of methodologies for rationally assessing degrees of confidence in predictions of contaminant transport.

\section{Summary and conclusions}

A set of tracer tests designed to provide detailed and accurate breakthrough data has been conducted in the Lincolnshire Limestone in the UK. Laboratory and preliminary field tests indicated that the fluorescent tracers used (fluorescein and amino G acid) were compatible in the field and exhibited identical behaviour to a conservative bromide tracer. Preliminary testing using a bromide tracer proved valuable in improving the quality of the collected data. The testing procedures, which were designed specifically to minimize the dispersive processes involved in injecting and monitoring concentration at the abstraction borehole, produced a set of detailed breakthrough curves with particularly well-defined tails.

Tests 1 and 4 were modelled with a simple dual porosity model using similar parameter sets, and the results from Test 4 were used successfully to predict the results of Test 2. The results of Test 3 showed a significant departure from this behaviour. The comparison of the results from Tests 1 and 3 emphasizes the danger in mistaking calibration for validation, the difficulty in predicting one result from the other using any model based upon assumptions of horizontal homogeneity, and the consequent uncertainty in making deterministic predictions of contaminant transport in fractured rock.

Data relating to the tracer tests are to be found at: http://www.bham.ac.uk/earthsciences/research/hydro/ tracertests

Acknowledgements. This paper forms part of a programme of research undertaken at the School of Earth Sciences of the University of Birmingham, the Fluid Processes Group of the British Geological Survey, and the Water Resource Systems Research Laboratory at the University of Newcastle, and has been funded jointly, under the 'Pollutant Transport in Soils and Rocks' special topic, by the Biotechnology and Biological Science Research Council (formerly the Agriculture and Food Research Council) and the Natural Environment Research Council. It is published with the permission of the Director of the British Geological Survey (Natural Environment Research Council).

The authors are indebted to all those who contributed to the field work (S. Gardner, S. Rogers, J. Davis and S. Dumpleton) and to J. Lloyd, G. Williams and R. Mackay whose advice has been invaluable.

\section{References}

BARKER, J. A. 1991. Transport in Fractured Rock. In: Downing, R. A. \& WiLkinson, W. B. (eds) Applied Groundwater Hydrology. Oxford University Press.

BiBBy, R. 1981. Mass transport of solutes in dual-porosity media. Water Resources Research, 17, 1075-1081.

Bear, J., Tsang, C. F. \& Marsily, G. De 1993. Flow and Contaminant Transport in Fractured Rock. Academic Press, New York.

Davis, S. N., Cambell, D. J., Bentley, H. W. \& Flynn, T. J. 1985. Groundwater tracers. National Groundwater Association. Co-operative agreement, CR-810036.

DAY, J. 1967. Hydrogeological map of North and East Lincolnshire. British Geological Survey, Keyworth, Nottingham.

Drost, W., Klotz, D., Koch, A., Moser, H., Neumaier, F. \& RAuERT, W. 1968. Point dilution methods of investigating groundwater flow by means of radioisotopes. Water Resources Research, 1, 125-146.

Greswell, R. 1995. Laboratory investigation of flow and transport processes in the Lincolnshire Limestones. $\mathrm{PhD}$ Thesis. University of Birmingham, U.K.

Greswell, R., Yoshida, K., Tellam, J. H. \& Lloyd, J. W. 1998. The micro-scale hydrogeological properties of the Lincolnshire Limestone, UK. Quarterly Journal of Engineering Geology, 31, 181-197.

Lever, D. A., Bradbury, M. H. \& Hemingway, S. J. 1983. Modelling the effect of diffusion into the rock matrix on radionuclide migration. Progress in Nuclear Energy, 12, 85-117.

Lloyd, J. W., Greswell, R., Williams, G. M., Ward, R. S., Mackay, R. \& Riley, M. S. 1996. An integrated study of controls on solute transport in the Lincolnshire Limestone. Quarterly Journal of Engineering Geology, 29, 321-339.

Novakowski, N. S. \& Lapcevic, P. A. 1994. Field measurement of radial solute transport in fractured rock. Water Resources Research, 30, 37-44.

Smalley, P. C., Bishop, P. K., Dickson, J. A. D. \& Emery, D. 1994. Water-rock interaction during meteoric flushing of a limestone: Implications for porosity development in karstified petroleum reservoirs. Journal of Sedimentary Research, A64(2), 180-189.

Smart, P. L. \& Laidlaw, I. M. S. 1977. An evaluation of some fluorescent dyes for water tracing. Water Resources Research, 13, 15-33.

Smettem, K. R. \& Trudgill, S. T. 1983. An evaluation of some fluorescent and non-fluorescent dyes in the identification of water transmission routes in soils. Journal of Soil Science, 34, 45-56.

Sudicky, E. A. \& Frind, E. O. 1982. Contaminant transport in fractured porous media: analytical solutions for a system of parallel fractures. Water Resources Research, 18, 1634-1642.

Sumbler, M. G., Lott, G. K. \& Berridge, N. G. 1990. Jurassic Limestones, Grantham, Lincolnshire. Field Trip B21, 1/9/90. 13th International Sedimentological Congress, Nottingham.

TANG, D. H., Frind, E. O. \& Sudicky, E. A. 1981. Contaminant transport in fractured porous media: analytical solution for a single fracture. Water Resources Research, 17, $555-564$. 
Zlotnik, V. A. \& Logan, J. D. 1996. Boundary conditions for convergent radial tracer tests and the effect of well bore mixing volume. Water Resources Research, 32, 2323-2328.
Zuber, A. \& MotyкA, J. 1994. Matrix porosity as the most important parameter of fissured rocks for solute transport at large scales. Journal of Hydrology, 158, 19-46.

Received 1 February 2000; accepted 9 October 2000. 